\title{
AUMENTO DEL CONTENIDO PROTEICO DE UNA BEBIDA A BASE DE AMARANTO (Amaranthus hypochondriacus)
}

\section{INCREASING THE PROTEIN CONTENT OF AN AMARANTH (Amaranthus hypochondriacus) DRINK}

\author{
Elizabeth Contreras L., Judith Jaimez O., Juan Carlos Soto R., \\ Aracelí Castañeda O., Javier Añorve M. \\ Laboratorio de Fisicoquímica de Alimentos 2, Área Académica de Química. \\ Universidad Autónoma del Estado de Hidalgo. México.
}

\begin{abstract}
The aim of this work was to increase the protein content of an amaranth drink (Amarantole) with different proteins sources (chickpea, pea, lacto serum, powdered milk and soybean milk). Different mixtures of Amarantole-protein mix were prepared in four proportions $(80: 20,75: 25,70: 30$ and 60:40). The best mixtures were selected according to the increase in the protein content and its sensory characteristics assayed by using degree of liking, preference and ranking test. Chemical and mineral composition was determined according to the AOAC techniques. Protein quality was determined by the Protein Efficiency Ratio test (PER) and in vivo digestibility. Amarantole-lacto serum show the highest $\%$ cent in protein content $(22.66 \%)$. The minerals more abundant in all the mixtures were $\mathrm{Ca}, \mathrm{K}$, $M g$ and Na. In general, all the mixtures presented highest values of PER (2.61 a 3.26) than the reference (casein $P E R=2.5)$ diet. Mixtures added of lactoserum and milk-lactoserum (88.19 y 86.0\%) presented a similar digestibility to the casein diet (91.28\%). In conclusion, Amarantole-lactoserum mixture showed the best characteristics concerning protein content, digestibility and PER value.
\end{abstract}

Key words: amaranth; atole; whey; protein; mexican drink.

Este trabajo fue recibido el 8 de Junio de 2011 y aceptado para ser publicado el 22 de Julio de 2011.

\section{INTRODUCCIÓN}

En países desarrollados, un ciudadano consume entre 80 y 121 g de proteínas por día. Esta cantidad es aproximadamente el doble de la ingesta diaria recomendada, la cual es de 0.8 a $1.5 \mathrm{~g} / \mathrm{kg}$ de peso corporal por día, dependiendo de la edad y género (1).

Un consumo inadecuado de proteína altera el crecimiento y la reparación del organismo, siendo especialmente peligrosa en los niños; problema muy común en los países subdesarrollados, en los que el consumo de proteína es relativamente bajo y por lo general, de origen vegetal. Sin embargo, si se mezclan determinados alimentos de origen vegetal como los cereales, con el frijol o cualquier otra leguminosa, se puede lograr una dieta rica en proteína y de buena calidad, este tipo de mezclas son accesibles, ya que estos alimentos se consumen en la mayoría de los países de América latina, entre ellos México (2).
Otra alternativa para mitigar y revertir los efectos de una inadecuada alimentación se da con el uso del amaranto, el cual es un recurso muy valioso y aplicable en el combate de la desnutrición (3). El amaranto pertenece a la familia Amaranthaceae y al género Amaranthus donde se consideran 11 especies diferentes de amaranto, de las cuales sólo las especies caudatus, cruentus e hipochondriacus, se utilizan para el consumo humano. Según criterios de la FAO, la OMS y otras instituciones internacionales, se considera al amaranto como un alimento de excelente calidad proteica, ya que se asemeja a la proteína ideal propuesta por la FAO (4) y con una digestibilidad similar a la del pan blanco (5). Además de disminuir el colesterol y los triglicéridos, mejora el metabolismo de la glucosa y de los lípidos $(6,7)$ y aumentar la concentración de Ca y P en los huesos (8).

Este cereal se ha empleado para elaborar películas biodegradables (9) y alimentos libres de gluten (10). En 
México se ha utilizado en una amplia variedad de alimentos, entre ellos de confitería y bebidas tradicionales a base de amaranto (amarantole). Este último ha sido parte de programas sociales de algunas dependencias gubernamentales quienes sugirieron un incremento del contenido proteico sin alterar el costo y las características sensoriales. El objetivo de este trabajo fue incrementar el contenido proteico del amarantole mediante la adición de diferentes fuentes de proteína vegetal y animal.

\section{MATERIAL Y MÉTODOS Preparación de las mezclas amarantole-fuente proteica}

El amarantole se definirá como una bebida no láctea en polvo preparada principalmente a base de amaranto reventado (Amaranthus hypochondriacus). Las muestras de amarantole con sabor a chocolate, fueron proporcionadas por una empresa ubicada en el estado de Hidalgo, México. Los ingredientes principales que componen la fórmula original son: harina de amaranto reventado, azúcar, sustituto de crema, colorante, saborizante artificial y benzoato de sodio. Por razones de confidencialidad fueron omitidas las cantidades.

Las fuentes proteicas fueron seleccionadas en base a la calidad de su proteína; las leguminosas complementan el perfil de aminoácidos del amaranto, las que se adquirieron en centros comerciales y tiendas naturistas de la ciudad de Pachuca, Hidalgo. Éstas fueron: proteína de lacto-suero (Prowinner®), leche en polvo (NIDO ${ }^{\circledR}$ clásica), harina de soya (Pronutri®), harina de alverja y de garbanzo. Para la obtención de estas dos últimas, los granos se sometieron a un proceso de cocción en olla de presión, durante 30 minutos. Una vez cocidos, se licuaron (licuadora marca Moulinex ${ }^{\circledR}$ ) con un poco de agua hasta obtener una pasta, la cual se deshidrató en una estufa (Felisa) a $60^{\circ} \mathrm{C}$ por 24 horas. Finalmente la pasta seca fue triturada manualmente en un mortero a fin obtener la harina.

Se prepararon mezclas de amarantole-fuente proteica en cuatro proporciones distintas: 80:20, 75:25, 70:30 y 60:40. Para el manejo de datos se utilizaron los siguientes códigos: amarantole + lactosuero (AS), amarantole + harina se soya (AHS), amarantole + harina de alverja (AR), amarantole + harina de garbanzo (AG), amarantole + leche en polvo (AL).

\section{Selección de las mejores proporciones de mezclas amarantole-fuente proteica}

Para la selección de las mejores proporciones de las mezclas, se realizaron pruebas sensoriales de preferencia y de grado de satisfacción utilizando 15 jueces semi-entrenados (11). Con la finalidad de conocer cuál era la muestra de mayor agrado, se aplicó una prueba de ordenamiento entre las mezclas seleccionadas utilizando 40 jueces no entrenados. Las mezclas seleccionadas fueron caracterizadas: se analizó la composición proximal y mineral, se determinó la calidad proteica de las mezclas mediante una prueba biológica (REP) y la digestibilidad.

\section{Análisis proximal y mineral de las mezclas amarantole-fuente proteica seleccionadas}

El análisis proximal (humedad, grasa, cenizas, fibra, proteína y carbohidratos por diferencia) de las mezclas seleccionadas se realizó de acuerdo a la metodología propuesta por la AOAC (12).

El análisis de minerales, se llevó a cabo mediante Espectrofotometría de Emisión Acoplada a Plasma (ICP por sus siglas en inglés, Perkin-Elmer xl-3000), mediante el método de flama, para lo cual las muestras se sometieron previamente a una digestión en microondas (Marx-X, potencia $1200 \mathrm{~W}$ ) programado según un método diseñado por la compañía CEM (North Carolina, U.S.A).

\section{Determinación de la calidad de la proteína de las mezclas amarantole-fuente proteica mediante la prueba biológica de Relación de Eficiencia Proteica (REP) y la digestibilidad in vivo}

Con el fin de evaluar la calidad proteica de las mezclas, se llevó a cabo la prueba biológica del REP. Para ello fue necesario elaborar una dieta isoproteínica e isoenergética con respecto a la dieta de referencia, que por lo general es caseína, una proteína considerada como ideal ya que posee todos los aminoácidos esenciales. Se utilizaron 6 ratas macho raza Wistar de 21 a 23 días de edad (recién destetadas). El ensayo tuvo una duración de 21 días (13).

La digestibilidad in vivo de las mezclas amarantolefuente proteica, se determinó midiendo la concentración de nitrógeno en heces (NF).

\section{Análisis estadístico}

Las determinaciones se realizaron por triplicado. Para el procesado de datos se utilizó el paquete SPSS versión 10.0. Para el análisis químico y las pruebas biológicas se aplicó un análisis de varianza de un factor (ANOVA de una vía), acoplado a la prueba de comparación múltiple de Duncan con un nivel de significancia del $0.05 \%$. La prueba de preferencia se interpretó según la tabla de resultados para pruebas de dos muestras, modelo unilateral con un nivel de significancia del 5\% (11).

La prueba de ordenamiento se interpretó según el método de los totales de rangos, se consultó la tabla de los totales de rangos requeridos a un nivel de significancia del 5\% (11). 


\section{RESULTADOS Y DISCUSIÓN}

\section{Selección de las mejores proporciones de mezcla amarantole-fuente proteica}

Los resultados de la prueba de grado de satisfacción mostraron que la proporción 75:25 fue la mejor calificada por los jueces para todas las mezclas, excepto AG que no fue del agrado de los consumidores en ninguna de las proporciones estudiadas. Los comentarios aportados por los consumidores indican que las principales razones del desagrado provocado por esta mezcla fue su sabor a grasa, por lo tanto, fue eliminada para ensayos posteriores. La proporción 60:40 de la mezcla AL obtuvo el $100 \%$ de respuestas "Me gusta", sin embargo presentó un claro predominio de sabor a leche en polvo por lo que tuvo que ser eliminada. Considerando lo anterior, se probó una nueva proporción (62.5:37.5) la cual también gustó al 100\% de los jueces.

Las proporciones de las mezclas amarantole-fuente proteica seleccionadas de acuerdo al agrado mostrado por los jueces fueron: 75:25 para AS, AHS y AR; 62.5:37.5 para AL y 62.5:25:12.5 para ASL. Conocido lo anterior, se aplicó una segunda prueba sensorial para conocer la preferencia de los consumidores por las mezclas amarantole-fuente proteica, comparadas con la fórmula original del amarantole. Los resultados obteni- dos muestran que todas las mezclas fueron preferidas significativamente sobre la fórmula original (nivel de significancia del 5\%). En el caso de la mezcla AL, el $100 \%$ de los jueces prefirieron dicha mezcla sobre la fórmula original.

Una vez seleccionadas las proporciones de las mezclas de acuerdo a su preferencia por el consumidor y establecida la preferencia de las mezclas respecto a la fórmula original, se realizó una prueba de ordenamiento para determinar cuál de las mezclas era la de mayor agrado. Los resultados se muestran en el gráfico 1. La mezcla de mayor puntuación y por consecuencia la seleccionada como de mayor agrado por el consumidor fue AL.

\section{Caracterización química y mineral de las mezclas amarantole-fuente proteica seleccionadas}

En la tabla 1 se muestra la composición química de las mezclas amarantole-fuente proteica que fueron seleccionadas en base a las pruebas sensoriales. El contenido de humedad de las mezclas analizadas varió de 2.95 a $4 \%$ y fue significativamente diferente excepto para AR y ASL. Todos los valores de humedad determinados se encontraron dentro del límite máximo establecido por la NOM-147-SSA1-1996 (14), la cual indica que las harinas no deben rebasar el $15 \%$ de

\section{GRÁFICO 1}

Resultados de la prueba de ordenamiento de las mezclas amarantole-fuente proteica.

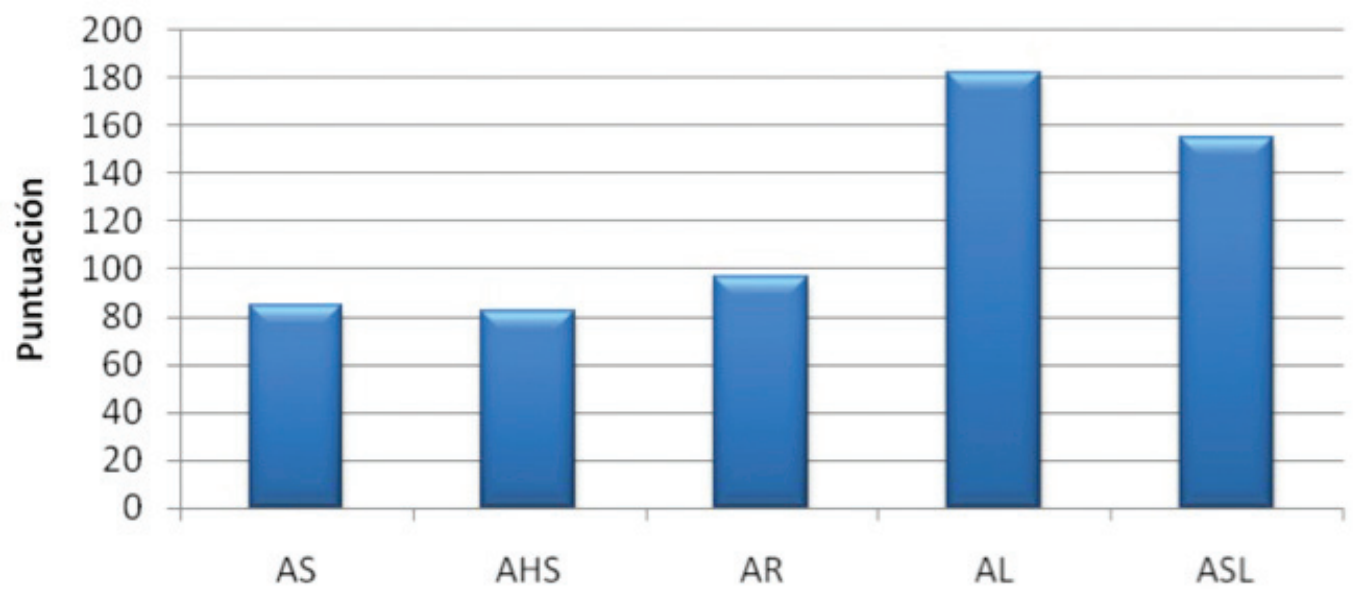

Muestra 
humedad, ya que se puede propiciar el desarrollo de bacterias y hongos que pueden alterar la calidad del producto.

Con respecto a las cenizas, el análisis estadístico realizado indicó la presencia de cuatro grupos de medias significativamente diferentes, siendo similar el contenido de cenizas en AL y ASL, lo cual se puede atribuir a la presencia de minerales provenientes de la leche en polvo. Porras (15) reportó un valor de $1.11 \%$ de cenizas para el amarantole sabor chocolate, todas las mezclas presentaron un incremento en el contenido de cenizas como consecuencia de la incorporación de las distintas fuentes proteicas. Sin embargo, el contenido de cenizas de todas las mezclas se encontró por debajo de los valores reportado por Bressani (16), quien indicó un valor de 2.6-4.4\% de cenizas en harinas de amaranto de todas las especies, lo cual se debe a que en la mezcla, la cantidad de harina de amaranto se reduce para ser sustituida por una fuente proteica.

En cuanto al contenido de grasa, el análisis estadístico realizado reveló la presencia de 3 grupos diferentes, siendo similar el contenido de grasa en AS, AHS y AR, las cuales presentaron un valor inferior al reportado por Porras (15) para el amarantole sabor chocolate (1.37\%). Esto puede ser debido a la sustitución parcial de la harina y al bajo aporte de grasa de las fuentes proteicas. Sin embargo, las mezclas AL y ASL presentaron valores más elevados debido a la grasa aportada por la leche en polvo. Todas las mezclas presentaron contenidos de grasa inferiores al 8.8-12.1\% reportado por Bressani (16) para harina de amaranto.

En relación al contenido de proteína, Porras (15), reportó un $4.64 \%$ para el amarantole sabor chocolate, las mezclas analizadas presentaron valores de 10.07 a $22.66 \%$ de proteína. Con la adición de proteína de lactosuero y leche en polvo más proteína de lactosuero, se alcanzó el porcentaje de proteína requerido (20\%) por la empresa.

Las mezclas AHS y AR presentaron el mayor porcentaje de fibra (3.18 y $2.4 \%$, respectivamente); debido al origen vegetal de la fuente proteica. La adición de las distintas fuentes proteicas impactó tanto en el contenido de proteína como en el de fibra. Sin embargo, estos contenidos resultaron inferiores al $5.17 \%$ reportado por Porras (15) para la harina de amaranto reventado, que puede explicarse por la presencia de otros ingredientes que constituyen la fórmula.

El contenido de carbohidratos de las mezclas analizadas se encontró entre el 68 y el $81 \%$. Estos valores son inferiores al $90.57 \%$ de carbohidratos reportados para el amarantole sabor chocolate (15) lo cual se debe a la incorporación de proteína, grasa y fibra proveniente de las diferentes fuentes proteicas que disminuye el contenido de carbohidratos.

Respecto a la composición mineral, el Mg y el K (gráficos 2 y 3 ) fueron los macrominerales más abun-

\section{TABLA 1}

Caracterización química de las mezclas seleccionadas (\%p/p \pm D.E; $\mathbf{n}=3)$

\begin{tabular}{|c|c|c|c|c|c|c|}
\hline Mezcla & Humedad & Cenizas & Grasas & Proteína & Fibra & CHO's \\
\hline $\begin{array}{l}\text { AS } \\
(75: 25)\end{array}$ & $4.00^{\mathrm{a}} \pm 0.07$ & $1.65^{\mathrm{a}} \pm 0.02$ & $1.17^{\mathrm{a}} \pm 0.02$ & $22.66^{a} \pm 0.09$ & $0.46^{b} \pm 0.03$ & 70.07 \\
\hline $\begin{array}{l}\text { AHS } \\
(75: 25)\end{array}$ & $2.95^{\mathrm{b}} \pm 0.24$ & $2.39^{b} \pm 0.06$ & $1.09^{a} \pm 0.09$ & $10.07^{b} \pm 0.12$ & $3.18^{\mathrm{e}} \pm 0.06$ & 80.32 \\
\hline $\begin{array}{l}\text { AR } \\
(75: 25)\end{array}$ & $3.67^{c} \pm 0.12$ & $1.32^{\mathrm{c}} \pm 0.02$ & $1.06^{\mathrm{a}} \pm 0.01$ & $10.12^{b} \pm 0.09$ & $2.40^{c} \pm 0.29$ & 81.43 \\
\hline $\begin{array}{l}\mathrm{AL} \\
(62.5: 37.5)\end{array}$ & $3.26^{\mathrm{d}} \pm 0.2$ & $2.53^{d} \pm 0.09$ & $7.02^{b} \pm 0.27$ & $12.28^{\mathrm{c}} \pm 0.12$ & $0.71^{\mathrm{d}} \pm 0.03$ & 74.22 \\
\hline $\begin{array}{l}\text { ASL } \\
(62.5: 25: 12.5)\end{array}$ & $3.57^{c} \pm 0.08$ & $2.52^{\mathrm{d}} \pm 0.14$ & $4.90^{c} \pm 0.20$ & $19.53^{\mathrm{d}} \pm 0.03$ & $1.12^{\mathrm{a}} \pm 0.09$ & 68.37 \\
\hline
\end{tabular}




\section{GRÁFICO 2}

Contenido de magnesio en las mezclas de la bebida de amaranto-fuente proteica $(n=3)$

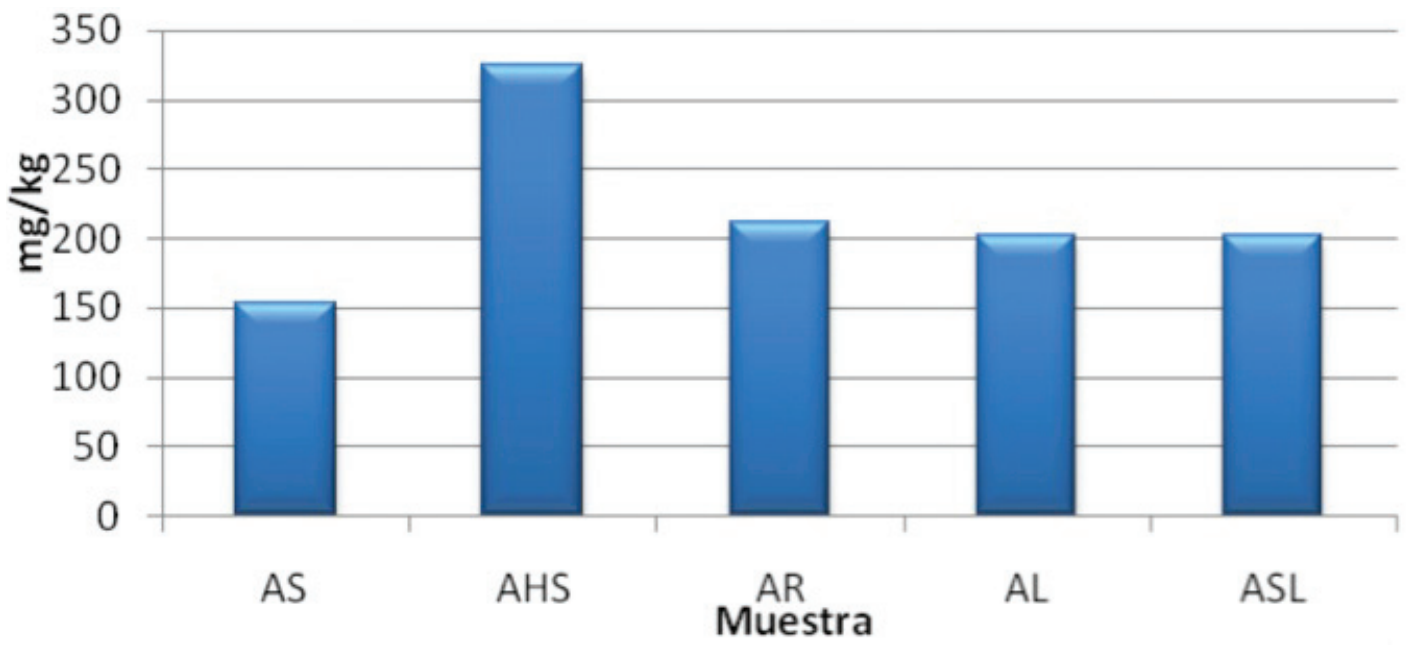

n: número de muestras, AS: Amarantole-lactosuero, AHS: Amarantole-harina de soya, AR: Amarantole-alverja,

AL: Amarantole-leche en polvo, ASL: Amarantole-leche en polvo-lactosuero. Los resultados presentaron un coeficiente de variabilidad < 5\%.

\section{GRÁFICO 3}

Contenido de potasio en las mezclas de la bebida de amaranto-fuente proteica $(n=3)$

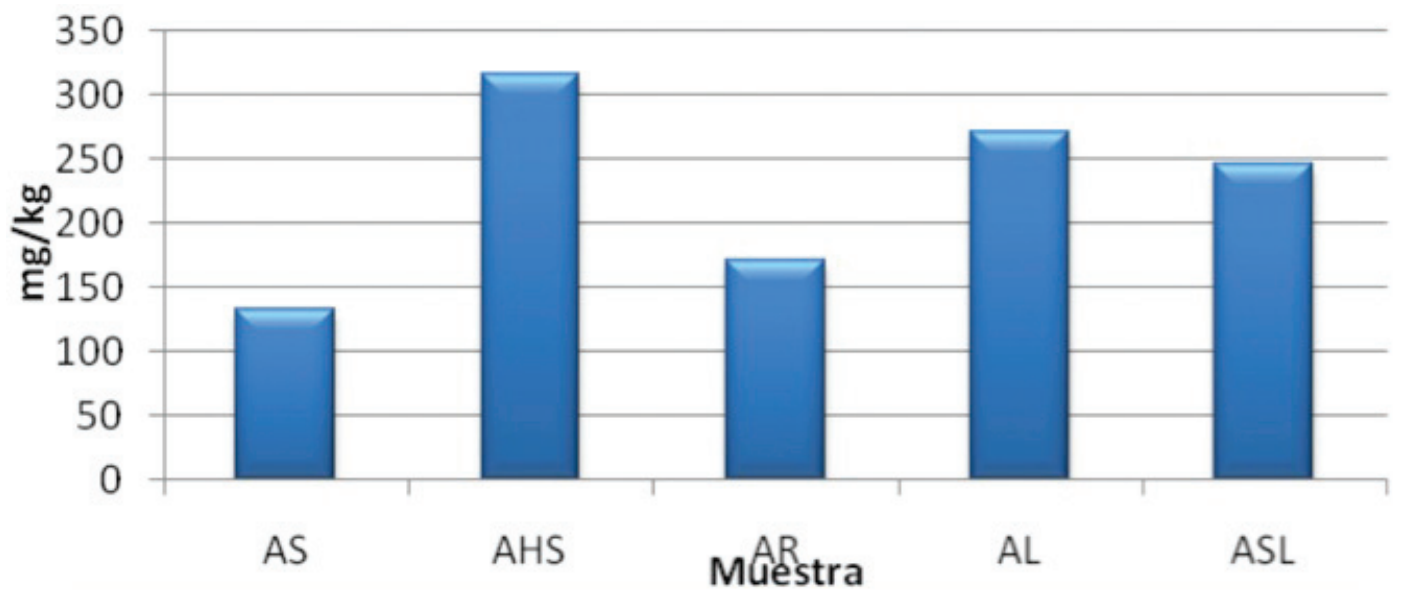

n: número de muestras, AS: Amarantole-lactosuero, AHS: Amarantole-harina de soya, AR: Amarantole-alverja,

AL: Amarantole-leche en polvo, ASL: Amarantole-leche en polvo-lactosuero. Los resultados presentaron un coeficiente de variabilidad $<5 \%$. 
dantes en todas las mezclas analizadas, seguidos del $\mathrm{Ca}$ y Na. La mezcla que presentó el mayor contenido de Mg fue AHS seguida de AR, debido a que las fuentes proteicas de estas mezclas (soya y alverja) son ricas en este mineral $(17,18)$; ésta mezcla se aproxima a la Ingesta Diaria Recomendada (IDR) de $350 \mathrm{mg} / \mathrm{día}$ de $\mathrm{Mg}$ (1). Para el potasio no se ha establecido una IDR, ya que se encuentra en la mayoría de los alimentos, sin embargo, se ha propuesto un consumo mínimo de 2000 $\mathrm{mg}$ /día (1). En general, todas las mezclas presentaron un bajo contenido de este mineral (menor a $320 \mathrm{mg}$ / $\mathrm{kg}$ ), siendo el más alto el de la mezcla AHS (gráfico 3 ).

El mayor contenido de calcio se encontró en ASL seguido de AL, debido a que estas mezclas contienen una fuente proteica de origen lácteo. Sin embargo, las mezclas adicionadas con fuentes proteicas de origen vegetal (alverja y soya) no presentan un aporte importante de este mineral.

Los resultados obtenidos para el sodio se encontraron entre los 100-400 mg/kg. Las mezclas que presentaron el mayor contenido de este mineral fueron AL y ASL, lo que puede deberse al contenido de sodio de las fuentes proteicas $(500 \mathrm{mg} / \mathrm{kg}$ para el suero de leche y $350 \mathrm{mg} /$ $\mathrm{kg}$ para la leche en polvo, según etiquetado). Ninguna de las mezclas alcanzó los requerimientos de la IDR, la cual indica un consumo de 500 a $2000 \mathrm{mg}$ al día (1).

Los microminerales analizados fueron: $\mathrm{B}, \mathrm{Cu}, \mathrm{Fe}$, Mn y Zn. En el caso del B, las mezclas presentaron valores inferiores a $0.2 \mathrm{mg} / \mathrm{kg}$, ninguna sobrepasó la IDR de $10 \mathrm{mg} / \mathrm{kg}$ (1). Para el Cu, las mezclas AS, AL y ASL presentaron contenidos inferiores a la IDR $(2 \mathrm{mg} / \mathrm{kg})$ (1), sin embargo las mezclas AHS y AR, sobrepasaron este requerimiento. Para el Fe se establece una IDR de 10-15 mg al día en niños y $10 \mathrm{mg}$ para adultos (1), la mezcla AL se ajusta a este parámetro. Sin embargo, en las mezclas con las fuentes proteicas de origen vegetal, se sobrepasó este valor debido al alto contenido de hierro que presentan ambas leguminosas $(17,18)$.

En el caso del Mn, todas las muestras sobrepasaron la IDR de $2.5 \mathrm{mg}$ al día (1). Los valores más elevados fueron para AHS y AR, debido a que la soya y la alverja pueden presentar altas concentraciones de este mineral $(17,18)$. La IDR para el zinc es de $15 \mathrm{mg} /$ día (1), la mezcla que se aproxima a este valor es AS mientras que AHS, AR y ASL lo sobrepasan.

En cuanto a metales pesados, la NOM-147SSA1-1996 (14) establece un límite máximo de $0.5 \mathrm{mg} /$ $\mathrm{kg}$ de plomo en cereales, harinas y derivados. Todas las muestras, a excepción de la mezcla AR, presentaron valores bajo el límite de detección para los tres metales analizados.

\section{Determinación de la calidad de la proteína de las mezclas amarantole-fuente proteica mediante la prueba biológica (REP) y la digestibilidad in vivo}

En la tabla 2 se muestran los datos del REP ajustado para las dietas de las mezclas realizadas, así como para la dieta control. Todas las mezclas, a excepción de la dieta con la mezcla AR, presentaron valores superiores a la dieta de caseína lo cual se debió a la disponibilidad de aminoácidos, ya que al parecer, con la adición de las diferentes fuentes proteicas se logró un buen balance de aminoácidos esenciales, lo cual se reflejó en la ganancia en peso de los animales. En la dieta con la mezcla AS,

\section{TABLA 2}

\section{REP ajustado de las mezclas amarantole-fuente proteica} $\left(\mathrm{REP}_{\text {ajustado }} \pm \mathrm{DE} ; \mathbf{n}=3\right)$

\begin{tabular}{lcr} 
Dieta & $\mathbf{R E P}_{\text {ajustado }}$ & $\mathbf{C V}$ \\
\hline Caseína & $2.50^{\mathrm{a}} \pm 0.18$ & 5.67 \\
AS & $3.26^{\mathrm{b}} \pm 0.25$ & 6.09 \\
AHS & $2.61^{\mathrm{a}, \mathrm{c}} \pm 0.12$ & 3.69 \\
AR & $1.70^{\mathrm{e}} \pm 0.26$ & 11.95 \\
AL & $2.72^{\mathrm{c}} \pm 0.21$ & 6.05 \\
ASL & $3.05^{\mathrm{d}} \pm 0.26$ & 6.62
\end{tabular}

DE: Desviación estándar, n: numero de muestras, AS: Amarantole-lactosuero, AHS: Amarantole-harina de soya, AR: Amarantole-alverja, AL: Amarantole-leche en polvo y ASL: Amarantole-leche en polvo-lactosuero.

Letras distintas denotan diferencia significativa con nivel de significancia de $0.05 \%$ 
se obtuvo un valor similar al reportado por la FAO para un concentrado de la proteína del suero de leche (REP 3.2) (4). AS presentó el valor más alto de REP de todo el experimento seguido por ASL cuyo valor de 3.05 de REP ajustado se explica por la calidad de la proteína del suero. La mezcla de AHS, fue estadísticamente similar a la dieta de referencia y a la mezcla AL, aunque en ésta se observó un mayor impulso del crecimiento de las ratas, sin embargo, el valor de REP ajustado encontrado no fue tan alto como el de AS, lo que se atribuye a que la dieta fue preparada al $9 \%$ de proteína. Según la FAO la harina de soya tiene un valor de REP ajustado de 2.2 (4), valor que resulta cercano al determinado en este estudio, lo que podría indicar que en esta mezcla la proteína se complementó, de modo que su composición de aminoácidos se asemeja más a los de la proteína ideal propuesta por la FAO. La dieta con la mezcla AR mostró el menor valor de REP ajustado, y con ello, una menor calidad de proteína con respecto a la dieta de referencia y a las demás mezclas analizadas, lo cual se puede atribuir a que la dieta fue preparada al $9 \%$ de proteína. Por otro lado, Gutiérrez y Lozano (19), reportaron la presencia de ácido fítico $(1.36 \%)$ en la harina de amaranto reventado, lo que al parecer podría afectar la absorción de minerales, repercutiendo de manera importante en el crecimiento de los animales de estudio.

Los valores de digestibilidad in vivo para las mezclas analizadas se presentan en la tabla 3 . El análisis estadístico realizado reveló cuatro grupos significativamente diferentes. La dieta de referencia a base de caseína presentó la digestibilidad más alta, aunque ésta fue similar a la mostrada por AS y ASL, de las muestras analizadas, estas dos mezclas fueron las de mayor digestibilidad, lo cual es debido a que la fuente de proteína de estas mezclas (proteína de lacto-suero) es de alta biodisponibilidad.

Las mezclas AHS y AR adicionadas con fuentes proteicas de origen vegetal, presentaron una menor digestibilidad, debido en parte a su contenido de fibra (tabla 1) y a que algunas proteínas por su naturaleza, son resistentes al ataque de enzimas proteolíticas o insolubles en agua como las proteínas denominadas globulinas (legumina y vincilina), de igual manera, las leguminosas contienen inhibidores de tripsina y lectinas (18). Las fuentes proteicas utilizadas presentaron valores de digestibilidad de 84 para la harina de soya y 82 para la alverja (4), lo cual explica los resultados obtenidos. La mezcla AL fue estadísticamente similar a AHS a pesar de que las proporciones de las fuentes proteicas fueron diferentes. La digestibilidad pudo haberse afectado por la posible presencia de tóxicos como el ácido fítico cuya presencia ha sido reportada en harina de amaranto (19).

En general, todas las fuentes de proteína empleadas tuvieron la capacidad de impulsar el crecimiento de los animales durante la prueba biológica realizada, lo que indicaría que se logró una buena calidad proteica en las mezclas. Amarantole-harina de soya presentó el mayor contenido de proteína, la mayor digestibilidad y el mayor valor de PER, sin embargo la mezcla amarantole-leche en polvo fue la mezcla de mayor agrado para los consumidores.

\section{RESUMEN}

El objetivo de este trabajo fue aumentar el contenido proteico de una bebida a base de amaranto (Amarantole) mediante la adición de diferentes fuentes proteicas (garbanzo, alverja, lactosuero, leche en polvo, leche de soya). Se prepararon mezclas de Amarantole-fuente

\section{TABLA 3}

\section{Digestibilidad "in vivo" de las mezclas amarantole-fuente proteica (Digestibilidad $\pm \mathrm{DE}, \mathrm{n}=3$ )}

\section{Dieta}

Caseína

AS

AHS

AR

AL

ASL
Digestibilidad "in vivo"

$91.28^{\mathrm{a}} \pm 1.80$

$88.19^{\mathrm{a}, \mathrm{b}} \pm 0.89$

$79.60^{\mathrm{c}} \pm 1.70$

$70.27^{\mathrm{d}} \pm 4.36$

$79.48^{\mathrm{c}} \pm 2.89$

$86.07^{\mathrm{b}} \pm 2.77$

DE: Desviación estándar, n: numero de muestras, AS: Amarantole-lactosuero AHS: Amarantole-harina de soya,

AR: Amarantole-alverja, AL: Amarantole-leche en polvo y ASL: Amarantole-lactosuero-leche en polvo.

Letras distintas denotan diferencia significativa a un nivel de significancia de $0.05 \%$ 
proteica en cuatro proporciones distintas $(80: 20,75: 25$, 70:30 y 60:40). Las mejores mezclas fueron seleccionadas en base a su aumento en el contenido proteico y sus características organolépticas detectadas mediante pruebas de grado de satisfacción, de preferencia y de ordenamiento. La composición química y mineral de las mezclas seleccionadas fue determinada mediante técnicas del AOAC. La calidad proteica se determinó a través de la prueba de Relación de Eficiencia Proteica (REP) y la digestibilidad in vivo. Amarantole-lactosuero alcanzó el porcentaje de proteína más elevado (22.66\%). Los minerales más abundantes en todas las mezclas fueron: $\mathrm{Ca}, \mathrm{K}, \mathrm{Mg}$ y $\mathrm{Na}$. En general, todas las mezclas, presentaron valores de REP (2.61 a 3.26) superiores a la dieta de referencia (caseína $\mathrm{REP}=2.5$ ). Las mezclas adicionadas de lactosuero y leche en polvo-lactosuero (88.19 y $86.0 \%)$ presentaron una digestibilidad similar a la dieta de caseína (91.28\%). En conclusión, la muestra Amarantole-lactosuero fue la mezcla que presentó las mejores características en cuanto a contenido de proteína, digestibilidad y valor de REP.

Palabras clave: amaranto; atole; lactosuero; proteína; bebidas mexicanas.

Dirigir la correspondencia a:

Profesora

Elizabeth Contreras López

Carretera Pachuca-Tulancingo,

km 4.5, C.P. 42184

Ciudad Universitaria.

Mineral de la Reforma, Hidalgo, México

Teléfono 017717172000 , extensión 2512

E-mail: eliclopez@yahoo.com.mx.

\section{BIBLIOGRAFÍA}

1. Instituto Nacional de Ciencias Médicas y Nutrición Salvador Zubirán (INCMNSZ). Ingestión Diaria Recomendada (IDR) de proteínas, vitaminas y nutrimentos inorgánicos para la población mexicana, 2001.

2. Latham MC. Nutrición humana en el mundo en desarrollo. Nueva York: Publicaciones de la Universidad de Cornell, 2002.

3. Sood A, Sharma HR, Verma R, Anand S. Amaranth, sesame and soybean supplemented nutritions sweet balls. Bhartiya Krishi Anushandhan Patrika 2009, 24(2): 33-6.

4. Fries AM, Morón C, Pérez AM, Rosero ME. Manual sobre la utilización de cultivos andinos subexplotados en la alimentación [Versión electrónica]. Santiago, Chile: FAO 2001_ [C [C 15 enero del 2009]. Disponible en: http://www.rlc.fao.org
5. Capriles VD, Coelho KD, Guerra-Matías AC, Areas JAG. Effects of processing methods on amaranth Storch digestibility and predicted glycemic index. J Food Sci 2008, 73(7):160-4.

6. Kyung KH, Jeong KM, Hoo SD. Improvement of lipid profile by amaranth (amaranthus esculantus) supplementation in streptozotocin induced diabetic rats. Ann Nutr Metab 2006; 50:277-81.

7. Martirosyan DM, Miroshnichenko LA, Kulakova SN, Pogojeva AV, Zoloedov VI. Amaranth oil application for coronary heart disease and hypertension, Lipids Health Dis 2007, 6:1.

8. Gambus H, Gambus F, Wrona P, Pastuszka D, Ziobro R, Nowotna A, Kopec A, Sikora M, Enrichment of gluten-free rolls with amaranth and flaxseed increases the concentration of calcium and phosphorus in the bones of rats. Polish Food Nutr Sci 2009, 59(4)349-55.

9. Mokrejs P, Langmaier F, Janacova D, Mladek M, Kolomaznik, Vasek V. Thermal study and solubility tests of Films base don amaranth flour Stach-protein hydrolysate. J Thermal Analyt Calorimetry 2009, 98:299-307.

10. Gambus H, Gambus F, Pastuszka D, Wrona P, Ziobro R, Sabat R, Mickowska B, Nowotna A, Sikora M. Quality of gluten free supplemented cakes and biscuits. Internat J Food Sci Nutr 2009, 60(54): 31-50.

11. Anzaldúa-Morales A. La evaluación sensorial de los alimentos en la teoría y en la práctica. España: Acribia, 1994.

12. AOAC. 1990. Official Methods of Analysis of the Association of Official Analytical Chemists. 1990. 15th ed. Arlington: AOAC. Vol. I \& II.

13. AOAC. 2000 Official Methods of Analysis of the Association of Official Analytical Chemists. 2000. 17th ed. Hoewitz: Gasthersburg, 2000.Vol. II.

14. Norma Oficial Mexicana. NOM-147-SSA1-1996. Bienes y servicios, cereales y sus productos, harinas de cereales, sémolas y semolinas. Alimentos a base de semillas comestibles, harinas, sémolas o semolinas y sus mezclas. Productos de panificación. Dispocisiones y especificaciones. México: Diario Oficial de la Federación.

15. Porras MG. Propiedades fisicoquímicas, microbiológicas y sensoriales de harinas para preparar atole a base de amaranto. Tesis de licenciatura. Química en Alimentos. Universidad Autónoma del Estado de Hidalgo, Pachuca, Hidalgo, México, 2009.

16. Bressani R. Composition and nutritional properties of amaranth. In: Paredes LO, editor. Amaranth biology, chemistry and technology. México: Instituto 
Politécnico Nacional, 1994.

17. Bravo E. Soya. Instrumento del control de la agricultura y la alimentación. Ecuador: HIVOS, 2005.

18. Ramos ME. Utilización de diversas leguminosas grano. Análisis de su valor nutritivo. Granada, España: Publicaciones de la Universidad de Granada,
2006.

19. Gutiérrez RJF, Lozano GS. Mejoramiento de las propiedades fisicoquímicas y sensoriales de la fórmula comercial de una bebida a base de amaranto. Tesis de licenciatura.Universidad Autónoma del Estado de Hidalgo, México, 2008. 